\title{
Development of batik design on mulberry silk waste/wool blended fabric using vinyl sulphone reactive dyes
}

Sushila and Sandeep Bains

Received: 25.11.2017; Revised: 08.04.2018; Accepted: 28.04.2018

See end of the paper for authors' affiliations

\section{Sushila}

Department of Apparel and

Textile Science, College of Home

Science, Punjab Agricultural

University, Ludhiana (Punjab)

India

Email : sushila.03ct@gmail.com
ABSTRACT : The study attempts to rematerialize the traditional art of Batik by studying the results obtained on mulberry silk and wool blended fabric. The objectives were to study the art of batik in detail and explore the possibilities of batik design development on mulberry silk/wool blended fabric with vinyl sulphone reactive dye (Cold reactive dyes). Dyeing time, $\mathrm{pH}$, and dye concentration were optimized for the dye and designs were prepared by use of batik method. Optical density of the dye solution was studied to determine the absorbency of dye from the dye solution at different $\mathrm{pH}$, time, and dye concentration. CIE Lab and $\mathrm{K} / \mathrm{S}$ values were also assessed for determining the optimum dyeing conditions. Good results were achieved when designs were developed and the dyed samples exhibited fair to good wash, light and perspiration fastness.

KEY WORDS: Dyeing, Wool, Silk, Blend, Vinyl suphone dyes, Batik, Colorfastness

- HOW TO CITE THIS PAPER : Sushila and Bains, Sandeep (2018). Development of batik design on mulberry silk waste / wool blended fabric using vinyl sulphone reactive dyes. Asian J. Home Sci., 13 (1) : 256-260, DOI: 10.15740/HAS/AJHS/13.1/256-260. Copyright@ 2018: Hind Agri-Horticultural Society. 